THE EFFECTIVENESS OF HEALTH EDUCATION WITH AUDIOVISUAL METHODS ON PARENTS MOTIVATION IN PRIVIDING ANTHELMINTIC AT PRIMARY SCHOOL

\title{
EFEKTIFITAS EDUKASI KESEHATAN DENGAN METODE AUDIOVISUAL TERHADAP MOTIVASI ORANG TUA DALAM MEMBERIKAN OBAT CACING PADA ANAK SEKOLAH DASAR
}

\author{
Ignasia Yunita Sari ${ }^{*}$
}

\begin{abstract}
Soil-transmitted helminths (STHs) infects $24 \%$ of the world's population, especially children and incerase morbidity. One of the intervention to overcome STHs is the administration of anthelmintic. Parental motivation is needed to increase for regularity in administration anthelmintic. Audiovisual easy to understand, encourages more curiosity and interesting. The purpose of this study was to determine of the effectiveness of health education using audiovisual methods on the motivation of parents in giving anthelmintic at Primary School. The research method used was a quasi experimental desain with pre-test and post-test nonequivalent control group. The control group was given education by using audiovisual method and the control grup with lectures. The analysis method uses wilcoxon test dan mann whitney test. The results showed that health education using audiovisual methods was effective in incerasing parents' motivation ( $p$ value 0,000 ). There was no difference in effectiveness of education using audiovisual methods and lectures in increasing parents' motivation.
\end{abstract}

Keywords : Audiovisual, Education, Helminths

\section{INTISARI}

Kecacingan menginfeksi 24\% penduduk dunia terutama pada anak-anak dan meningkatkan angka morbiditas. Salah satu intervensi mengatasi kecacingan adalah pemberian obat cacing. Motivasi orang tua diperlukan untuk keteraturan dalam pemberian obat cacing pada anak. Edukasi yang tepat diperlukan untuk meningkatkan motivasi orang tua. Media audiovisual menarik, mudah dimengerti dan mendorong kengingintahuan lebih banyak. Penelitian ini bertujuan untuk mengetahui efektifitas edukasi menggunakan metode audiovisual terhadap motivasi orang tua untuk pemberian obat cacing pada anak Sekolah Dasar. Desain penelitian yang digunakan adalah quasi experiment dengan pendekatan pre test and posttest nonequivalent control group. Enam puluh empat sampel

\author{
Afiliasi Penulis \\ STIKES Bethesda Yakkum Yogyakarta \\ Korespondensi kepada \\ Ignasia Yunita Sari \\ ignasia@stikesbethesda.ac.id
} dibagi menjadi 30 kelompok kontrol dan 34 kelompok intervensi. Kelompok kontrol diberikan edukasi dengan metode audiovisual dan kelompok kontrok dengan ceramah. Analisis data menggunakan wilcoxon test dan mann whitney test. Hasil studi menunjukkan edukasi kesehatan edukasi kesehatan dengan metode audiovisual efektif dalam meningkatkan motivasi orang tua ( $p$ value 0,000$)$. Tidak ada perbedaan 
keefektifan edukasi menggunakan metode audiovisual dan ceramah dalam meningkatkan motivasi orang tua ( $p$ value 0,225 ).

Kata kunci: Audiovisual, Edukasi, Kecacingan

\section{PENDAHULUAN}

Sepertiga dari populasi global, terutama negara berkembang terinfeksi cacing yang ditularkan oleh tanah (Bieri, 2013). Infeksi parasit ini dihubungkan dengan kemiskinan, lokasi pedesaan, sanitasi yang tidak memadahi dan pembuangan limbah. Di sisi lain, kecacingan menimbulkan masalah yang serius. World Health Organization (WHO) merilis Soil Transmitted Helminths (STH) menginfeksi tidak kurang dari 1,5 miliar individu di dunia atau $24 \%$ dari total populasi dunia. Daerah yang banyak mengalami kecacingan ini adalah daerah tropis dan sub tropis seperti Amerika, Sub-Sahara Afrika, Cina, serta Asia Timur. Data WHO tahun 2016 menunjukkan banyak anak usia prasekolah dan sekolah tinggal di daerah dimana cacing ini dapat ditransmisikan dengan mudah, sehingga membutuhkan pencegahan maupun pengobatan. Lebih dari 270 juta anak usia prasekolah dan 600 juta anak usia sekolah tinggal didaerah tersebut. (WHO, 2016). Data yang diperoleh dari Departemen Kesehatan, angka kejadian kecacingan di Indonesia mencapai 28\% (Depkes, 2013). Prevalensi kecacingan pada anak di Indonesia tahun 2002-2009 adalah 31,8\%. Sleman merupakan kabupaten dengan prevalensi tertinggi di DI Yogyakarta yaitu sebesar 21,78\% (Direktorat Jendral PP \& PL KemenKes RI, 2012).

Dampak yang diakibatkan kecacingan tidak langsung terlihat karena masyarakat sering menganggap penyakit kecacingan ini sebagai penyakit yang remeh. Akibat kecacingan antara lain bayi dengan berat badan lahir rendah, anemia, permasalahan ketika ibu bersalin, mengantuk, lemas, malas belajar, IQ menurun, bahkan prestasi dan produktivitas menurun (Depkes, 2010). Tatalaksana kecacingan adalah yang meliputi pengobatan cacing, kebersihan air, sanitasi dan kebersihan lingkungan (Campbell, 2016) Pengobatan cacing harus dilakukan secara rutin. Semua pihak harus berperan dalam mencegah kecacingan, baik pemerintah, keluarga, masyarakat, dan anak. Motivasi orangtua meningkatkan rasa kepedulian anak, maka perlu adanya dukungan dan motivasi dari orangtua sebagai lingkungan utama anak (Direktorat Jendral PP \& PL KemenKes RI, 2012). Salah satu faktor yang mempengaruhi terjadinya kecacingan pada anak-anak adalah pola asuh orang tua.

Kecacingan dapat dicegah melalui perilaku ibu seperti memberikan obat secara teratur.Anak usia sekolah dasar masih membutuhkan keterlibatan orangtua dalam mengonsumsi obat cacing. Kepatuhan dalam mengonsumsi obat cacing harus sesuai petunjuk petugas kesehatan dan tindakan dalam kepatuhan pada anak ini masih didominasi oleh orangtua. Orangtua yang sedikit menerima informasi akan berpengaruh dalam frekuensi minum obat cacing pada anak sesuai aturan. Anak belum bisa mandiri dalam mengonsumsi obat cacing (Cholifah, 2016). Agar orangtua berperan dengan baik dalam memberikan obat cacing pada anak, orangtua membutuhkan informasi dan motivasi. Peningkatan informasi dan motivasi dapat dilakukan dengan edukasi. Motivasi orang tua yang baik diharapkan meningkatkan perilaku pemberian obat cacing.

Promosi kesehatan dapat diberikan melalui penyuluhan kepada anak usia sekolah melalui program UKS sedangkan untuk masyarakat luas bisa mendapat promosi 
kesehatan melalui posyandu, media baik cetak maupun elektronik dan penyuluhan secara langsung. Kementerian Kesehatan RI Direktorat Jendral PP \& PL, 2012). Penggunaan media audiovisual melibatkan banyak indera dan bagian tubuh, seperti telinga (audio) dan mata (visual), yang membuat informasi atau pesannya mudah dimengerti. Kelebihannya media ini yaitu mudah dimengerti, mendorong kengingintahuan lebih banyak, mempercepat penyerapan pemahaman karena berbentuk audio dan visual, serta tidak membosankan bagi anak-anak (Sudjana, 2011). Penelitian sebelumnya telah banyak dilakukan, namun pada penelitian ini berbeda pada metode penelitian yang digunakan.

\section{METODE}

Desain penelitian adalah quasi experiment dengan desain pre test and posttest nonequivalent control group untuk mengetahui efektifitas edukasi kesehatan dengan metode audiovisual terhadap motivasi orang tua dalam memberikan obat cacing di SD Sanjaya Tritis Purwobinangun Pakem Sleman. Populasi yang digunakan adalah seluruh orang tua dari seluruh siswa Sekolah
Dasar (SD) Sanjaya, Tritis, Purwobinangun, Pakem, Sleman, Yogyakarta dengan jumlah 72 orang. Metode sampling yang digunakan adalah purposive sampling. Dengan jumlah responden sebanyak 64 responden yang dibagi menjadi 34 kelompok intervensi dan 30 kelompok kontrol. Kelompok intervensi diberikan edukasi dengan metode audiovisual, sedangkan kelompok kontrol diberikan edukasi dengan metode standar yaitu ceramah. Kriteria inklusi adalah orang tua siswa yang terdaftar di SD Sanjaya Tritis yang bersedia menjadi subjek penelitian melalui inform consent. Orang tua yang bisa membaca dan menulis dan tidak ada gangguan penglihatan dan pendengaran. Edukasi dilaksanakan di sekolah pada saat orang tua mengambil raport. Analisis data menggunakan uji wilcoxon dan mann withney dengan tingkat kepercayaan $95 \%$.

\section{HASIL DAN PEMBAHASAN}

Hasil dan pembahasan dari penelitian yang berjudul Efektifitas Edukasi Kesehatan dengan metode audiovisual terhadap motivasi orang tua dalam memberikan obat cacing di Sekolah Dasar. Proses penelitian dijelaskan sebagai berikut :

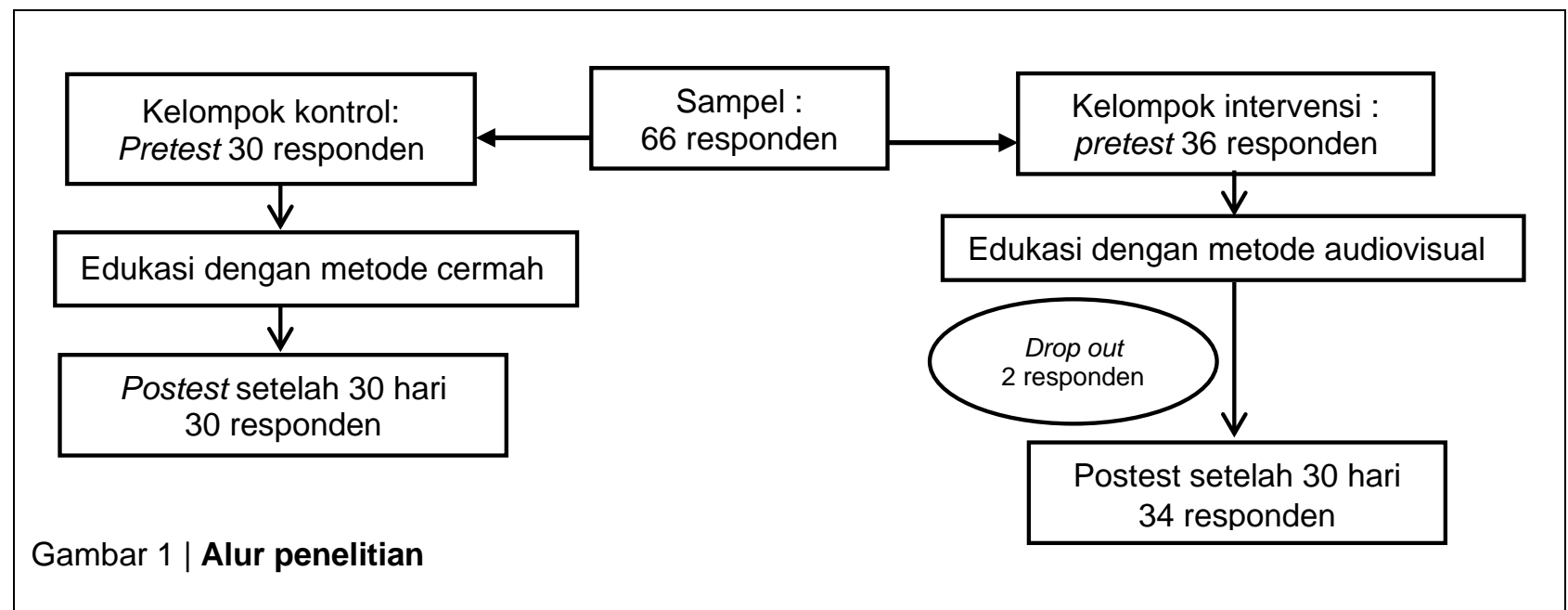


Hasil penelitian tentang karakteristik responden berdasarkan usia, jenis kelamin, pekerjaan, dan pendidikan dapat diuraikan sebagai berikut :

Tabel 1 | Karakteristik Responden Kelompok Kontrol dan Kelompok Intervensi

\begin{tabular}{clcccc}
\hline No. & \multicolumn{1}{c}{$\begin{array}{c}\text { Karakteristik } \\
\text { Responden }\end{array}$} & \multicolumn{2}{c}{ Kelompok intervensi } & \multicolumn{2}{c}{ Kelompok kontrol } \\
\cline { 2 - 5 } 1. & Usia Orangtua & Frekuensi & $\%$ & Frekuensi & $\%$ \\
& 20-35 tahun & 20 & 58,8 & 14 & 46,7 \\
& 36-50 tahun & 14 & 41,2 & 16 & 53,3 \\
\hline 2. & Jenis kelamin & & & & \\
& Laki-laki & 10 & 29,4 & 2 & 6,7 \\
& Perempuan & 24 & 70,6 & 28 & 93,3 \\
\hline 3. & Status Pekerjaan & & & & \\
& Bekerja & 24 & 70,6 & 16 & 53,3 \\
& Tidak bekerja & 10 & 29,4 & 14 & 46,6 \\
\hline 4. & Pendidikan & & & & 30 \\
& SD-SMP & 15 & 44,2 & 18 & 60 \\
& SMA & 18 & 52,9 & 3 & 10 \\
\hline & Perguruan tinggi & 1 & 2,9 & $\mathbf{3 0}$ & $\mathbf{1 0 0}$ \\
\hline
\end{tabular}

Analisis : Responden kelompok intervensi paling banyak berusia 36-50 tahun dan kelompok kontrol usia 20-35 tahun. Jenis kelamin paling banyak adalah perempuan, baik kelompok intervensi maupun kontrol.
Pada kedua kelompok, sebagian besar responden bekerja. Mayoritas pendidikan responden adalah SMA. Hasil penelitian karakteristik anak berdasarkan usia dan jenis kelamin, diuraikan sebagai berikut :

Tabel 2 | Karakteristik Anak Kelompok Kontrol dan Kelompok Intervensi

\begin{tabular}{llcccc}
\hline \multirow{2}{*}{ No. Karakteristik Responden } & \multicolumn{2}{c}{ Kelompok intervensi } & \multicolumn{2}{c}{ Kelompok kontrol } \\
\cline { 3 - 5 } & & Frekuensi & $\%$ & Frekuensi & $\%$ \\
\hline 1. & Usia Anak & & & 16 & 53,3 \\
& 6-9 tahun & 18 & 52,9 & 14 & 46,7 \\
& 10-12 tahun & 16 & 47,1 & 19 & 63,3 \\
\hline 2. & Jenis kelamin anak & & & 11 & 36,7 \\
& Laki-laki & 17 & 50,0 & $\mathbf{3 0}$ & $\mathbf{1 0 0}$ \\
& Perempuan & 17 & 50,0 & \\
\hline
\end{tabular}

Analisis : Sebagian besar anak berusia 6-9 tahun baik kelompok kontrol dan intervensi. Pada kelompok intervensi proporsi anak laki-laki dan perempuan sama. Pada kelompok kontrol anak laki-laki mendominasi. Motivasi orang tua memberikan obat cacing 
sebelum dan sesudah diberikan edukasi kesehatan dengan menggunakan metode ceramah.

Tabel 3 | Motivasi Orang Tua Memberikan Obat Cacing pada Anak Sebelum dan Sesudah Diberikan Edukasi Kesehatan dengan Metode Cermah

\begin{tabular}{llccccc}
\hline No. & Motivasi & \multicolumn{2}{c}{ Sebelum Intervensi } & \multicolumn{2}{c}{ Sesudah Intervensi } & \multirow{2}{*}{$\boldsymbol{P}$ Value } \\
\cline { 3 - 6 } & Orang tua & Frekuensi & $\%$ & Frekuensi & $\%$ & \\
\hline 1. & Tinggi & 14 & 46.7 & 23 & 76.7 & 0,002 \\
2. & Sedang & 14 & 46.7 & 7 & 23.3 & \\
3. & Rendah & 2 & 6.6 & 0 & 0 & \\
\cline { 1 - 5 } & Jumlah & 30 & 100 & 30 & 100 & \\
\hline
\end{tabular}

Analisis : Orang tua yang memiliki motivasi tinggi untuk memberikan obat cacing pada anak sebelum edukasi menggunakan metode ceramah adalah 14 orang dan setelah diberikan intervensi edukasi menggunakan metode ceramah menjadi 23 orang. Ada perbedaan motivasi sebelum dan sesudah diberikan edukasi dengan metode ceramah (pvalue 0,002). Motivasi orang tua memberikan obat cacing sebelum dan sesudah diberikan edukasi kesehatan dengan menggunakan audiovisual.

Tabel 4 | Motivasi Orang Tua Memberikan Obat Cacing pada Anak Sebelum dan Sesudah Diberikan Edukasi Kesehatan Dengan Audiovisual

\begin{tabular}{llccccc}
\hline \multirow{2}{*}{ No. } & \multirow{2}{*}{ Motivasi Orang Tua } & \multicolumn{2}{c}{ Sebelum Intervensi } & \multicolumn{2}{c}{ Sesudah Intervensi } & \multirow{2}{*}{ P Value } \\
\cline { 3 - 6 } & & Frekuensi & $\%$ & Frekuensi & $\%$ & \\
\cline { 1 - 5 } 1. & Tinggi & 17 & 50,0 & 30 & 88,2 & \\
\cline { 1 - 5 } 2. & Sedang & 15 & 44,1 & 4 & 11,8 & \multirow{2}{*}{0,00} \\
\cline { 1 - 5 } 3. & Rendah & 2 & 5,9 & 0 & 0 & \\
\hline & Jumlah & 34 & 100 & 34 & 100 \\
\hline
\end{tabular}

Analisis : Orang tua yang memiliki motivasi tinggi untuk memberikan obat cacing pada anak sebelum edukasi menggunakan audiovisual adalah 17 orang dan setelah diberikan intervensi edukasi menggunakan audiovisual menjadi 30 orang. Ada perbedaan motivasi sebelum dan sesudah diberikan edukasi dengan audiovisual (pvalue 0,000). Perbedaan motivasi orang tua setelah diberikan edukasi dengan metode audiovisual dan ceramah.

Tabel 5 | Motivasi Orang Tua Memberikan Obat Cacing Pada Anak Setelah Diberikan Edukasi Kesehatan Dengan Metode Audiovisual dan Ceramah

\begin{tabular}{llccccc}
\hline \multirow{2}{*}{ No. } & \multirow{2}{*}{ Motivasi Orang Tua } & \multicolumn{2}{c}{ Sebelum Intervensi } & \multicolumn{2}{c}{ Sesudah Intervensi } & \multirow{2}{*}{ P Value } \\
\cline { 1 - 5 } & & Frekuensi & $\%$ & Frekuensi & $\%$ & \\
\hline 1. & Tinggi & 30 & 88,2 & 23 & 76.7 & \multirow{2}{*}{0,225} \\
\hline 2. & Sedang & 4 & 11,8 & 7 & 23.3 & \\
\hline
\end{tabular}




\begin{tabular}{|c|c|c|c|c|c|c|}
\hline \multirow{2}{*}{ No. } & \multirow{2}{*}{ Motivasi Orang Tua } & \multicolumn{2}{|c|}{ Sebelum Intervensi } & \multicolumn{2}{|c|}{ Sesudah Intervensi } & \multirow{2}{*}{ P Value } \\
\hline & & Frekuensi & $\%$ & Frekuensi & $\%$ & \\
\hline 3. & Rendah & 0 & 0 & 0 & 0 & \\
\hline & Jumlah & 34 & 100 & 30 & 100 & \\
\hline
\end{tabular}

Analisis : berdasarkan tabel 5 tidak terdapat perbedaan motivasi orang tua dalam memberikan obat cacing pada anak setelah edukasi menggunakan media audiovisual dan ceramah ( $p$-value 0,225).

Berbagai negara berkembang mencoba mengembangkan metode dan stategi untuk mengurangi angka kecacingan, di India menerapkan pemberian obat cacing dan edukasi. Edukasi meliputi kebersihan dan kesinambungan dalam pemberian obat cacing (Aggarwal, 2018). Mascarini (2011) menyebutkan bahwa strategi untuk pengurangan infeksi STH adalah dengan pemberian obat cacing, pendidikan kesehatan, sanitasi dan kebersihan diri serta vaksin.

Hasil penelitian sejalan dengan penelitian Beiri (2013), Paket edukasi kesehatan mampu meningkatkan pengetahuan dan penurunan kejadian infeksi cacing. Intervensi pendidikan kesehatan dengan basis sekolah efektif dalam meningkatkan pengetahuan mengenai STH dan mengurangi infeksi Ascaris lumbricoides (Gyorkos, 2013). Rivero (2017) menyebutkan pemberian pendidikan kesehatan berkontribusi dalam pengetahuan dan pemahaman mengenai penularan infeksi STH, sehingga masyarakat mampu mencegah infeksi STH. Penggunaan media audiovisual melibatkan berbagai indera dan organ tubuh, seperti telinga (audio) dan mata (visual), yang memungkinkan informasi atau pesannya mudah dimengerti. Kelebihannya media ini yaitu mudah dimengerti, mendorong keingintahuan lebih banyak, mempercepat penyerapan pemahaman karena berbentuk audio dan visual, serta tidak membosankan bagi anak-anak (Sudjana, 2011). Berbagai penelitian menunjukan edukasi dengan audiovisual terbukti efektif, karena melibatkan banyak indra dan menarik. Penelitian Kapti (2013) menunjukkan pengetahuan dan sikap ibu dalam menangani diare pada anak meningkat dengan edukasi menggunakan media audiovisual. Edukasi dengan audiovisual juga terbukti meningkatkan motivasi, perilaku dan tindakan dalam mencegah DHF (Arneliwati, 2019).

Hasil penelitian yang dilakukan peneliti didukung oleh United Nations International Children's Emergency Fund Rwanda (2014) dimana $100 \%$ caregivers dengan tingkat ekonomi tinggi memberikan obat cacing pada anak mereka. Enam dari 10 responden selalu memberikan obat cacing pada anak setiap 3 bulan sekali, $89 \%$ menggunakan obat dari tenaga kesehatan, 7\% menggunakan herbal dan $4 \%$ menggunakan salah satu dari herbal atau obat dari tenaga kesehatan yang tersedia saat pengobatan kecacingan. Motivasi orang tua yang baik diharapkan meningkatkan pemberian obat cacing secara teratur.

\section{KESIMPULAN}

\begin{tabular}{l}
\hline Edukasi kesehatan dengan metode \\
audiovisual dan ceramah efektif dalam \\
meningkatkan motivasi orang tua dalam \\
memberikan obat cacing pada anak. Tidak \\
ada perbedaan keefektifan pemberian edukasi \\
kesehatan dengan metode audiovisual dan \\
ceramah.
\end{tabular}

\section{APRESIASI}

Terima kasih peneliti sampaikan kepada STIKES Bethesda Yakkum Yogyakarta atas pendanaan penelitian dosen pemula. 


\section{DAFTAR PUSTAKA}

Aggarwal, A., Mehta, S., Gupta, D., Sheikh, S., Pallagatti, S., Singh, R., \& Singla, I. (2012). Clinical \& immunological erythematosus patients characteristics in systemic lupus Maryam. Journal of Dental Education, 76(11), 1532-1539. https://doi.org/10.4103/ijmr.IJMR

Arneliwati, Agrina, \& Dewi, A. P. (2019). The effectiveness of health education using audiovisual media on increasing family behavior in preventing dengue hemorrhagic fever (DHF). Enfermeria clinica, 29 Suppl 1, 30-33. https://doi.org/10.1016/j.enfcli.2018.11.0 13

Bieri, F. A., Gray, D. J., Williams, G. M., Raso, G., Li, Y. S., Yuan, L., He, Y., Li, R. S., Guo, F. Y., Li, S. M., \& McManus, D. P. (2013). Health-education package to prevent worm infections in Chinese school children. New England Journal of Medicine, 368(17), 1603-1612. https://doi.org/10.1056/NEJMoa1204885

Campbell, S. J., Nery, S. V., McCarthy, J. S., Gray, D. J., Soares Magalhães, R. J., \& Clements, A. C. A. (2016). A Critical Appraisal of Control Strategies for SoilTransmitted Helminths. Trends in Parasitology, 32(2), 97-107. https://doi.org/10.1016/j.pt.2015.10.006

Cholifah. (2016). Promosi Kesehatan Dalam Pemberian Minum Obat Cacing Dan Kejadian Kecacingan Oxyuris Vermicularis. Diakses pada 17 September 2019 dari http://ejournal.stikesmuhkudus.ac.id/inde x.php/karakter/article/viewFile/235 $/ 171$
Depkes. (2013). KemenKes Berkomitmen Eliminasi Filariasis dan Kecacingan. Diakses pada 1 Februari 2019 dari http://www.depkes.go.id/article/view/238 2/kemenkes-berkomitmen-eliminasifilariasis-dan-kecacingan.html

Depkes. (2010). Penyakit Kecacaingan Masih Dianggap Sepele. Diakses pada 17 September $2016 \quad$ dari http://www.depkes.go.id/article/view/113 5/penyakit-kecacingan-masih-dianggapsepele.html

Direktorat Jenderal PP dan PL KeMenKes RI. (2012). Pedoman Pengendalian Kecacingan. Diakses pada 14 Oktober 2016

dari https://www.scribd.com/document/27985 9073/Pedoman-Pengendalian-PenyakitKecacingan-Kemenkes-2012

Gyorkos, T. W., Maheu-Giroux, M., Blouin, B., \& Casapia, M. (2013). Impact of health education on soil-transmitted helminth infections in schoolchildren of the Peruvian Amazon: a cluster-randomized controlled trial. PLoS Neglected Tropical Diseases, $7(9)$. https://doi.org/10.1371/journal.pntd.0002 397

Kapti, Rinik Eko, Yeni R., Widyatuti (2013). Efektifitas Audiovisual Sebagai Media Penyuluhan Kesehatan Terhadap Peningkatan Pengetahuan Dan Sikap lbu Dalam Tatalaksana Balita Dengan Diare di Dua Rumah Sakit Kota Malang. Jurnal IImu Keperawatan, Vol. I, No. 1, Mei 2013; diakses di https://jik.ub.ac.id/index.php/jik/article/vie w/52/73 
Mascarini-Serra, L. (2011). Prevention of soiltransmitted helminth infection. Journal of Global Infectious Diseases, 3(2), 175$182 . \quad$ https://doi.org/10.4103/0974$777 X .81696$

Rivero, M. R., Salas, M. M., Valente, R., Nores, M. J., De Angelo, C., Arrabal, J., Costa, S., \& Salomón, O. D. (2017). Prevention of intestinal parasites in a tri-border area of Latin America: Children perceptions and an integral health education strategy. Zoonoses and Public Health, 64(8), 673683. https://doi.org/10.1111/zph.12365

Sudjana, Nana. (2011). Penilaian Hasil Proses Belajar Mengajar. Bandung: PT Remaja Rosdakarya

UNICEF Rwanda. (2014). Knowledge, Attitudes and Practices Assessment on Early Nurturing of Children Report. Rwanda : Ministry of Health, Rwanda dan UNICEF Rwanda.

WHO. (2016). Soil-transmitted helminth infections. Diakses pada 14 Oktober 2019 dari http://www.who.int/mediacentre/factshee ts/fs366/en/ 